\title{
Aberrant mRNA Processing of the Maize Rp1-D Rust Resistance Gene in Wheat and Barley
}

\author{
Michael A. Ayliffe, ${ }^{1}$ Martin Steinau, ${ }^{2}$ Robert F. Park, ${ }^{3}$ Lee Rooke, ${ }^{1}$ Maria G. Pacheco, ${ }^{2}$ Scot H. Hulbert, ${ }^{2}$ \\ Harold N. Trick, ${ }^{2}$ and Anthony J. Pryor ${ }^{1}$ \\ ${ }^{1}$ CSIRO Plant Industry, Box 1600, Canberra, ACT, 2601, Australia; ${ }^{2}$ Department of Plant Pathology, Throckmorton Plant \\ Science Center, Kansas State University, Manhattan 66505, U.S.A.; ${ }^{3}$ The University of Sydney, Plant Breeding Institute \\ Cobbitty, Private Bag 11, Camden NSW, 2570, Australia
}

Submitted 2 September 2003. Accepted 15 March 2004.

\begin{abstract}
The maize $R p 1-D$ gene confers race-specific resistance against Puccinia sorghi (common leaf rust) isolates containing a corresponding $\operatorname{avrRp1-D}$ avirulence gene. An $R p 1-D$ genomic clone and a similar $R p 1-D$ transgene regulated by the maize ubiquitin promoter were transformed independently into susceptible maize lines and shown to confer $R p 1-D$ resistance, demonstrating that this resistance can be transferred as a single gene. Transfer of these functional transgenes into wheat and barley did not result in novel resistances when these plants were challenged with isolates of wheat stem rust (P. graminis), wheat leaf rust $(P$. triticina), or barley leaf rust $(P$. hordei). Regardless of the promoter employed, low levels of gene expression were observed. When constitutive promoters were used for transgene expression, a majority of $R p 1-D$ transcripts were truncated in the nucleotide binding site-encoding region by premature polyadenylation. This aberrant $\mathrm{mRNA}$ processing was unrelated to gene function because an inactive version of the gene also generated such transcripts. These data demonstrate that resistance gene transfer between species may not be limited only by divergence of signaling effector molecules and pathogen avirulence ligands, but potentially also by more fundamental gene expression and transcript processing limitations.
\end{abstract}

Additional keywords: cereal, $R$ gene.

Over the last decade, more than 20 resistance genes $(R$ genes) have been identified that encode proteins which recognize corresponding pathogen avirulence $(A v r)$ gene products. These $\mathrm{R}$ proteins can determine the recognition of a diversity of organisms, including viruses, bacteria, nematodes, aphids, and fungi (Staskawicz et al. 1995). The isolation of $R$ genes enables their transfer from donor species into sexually incompatible recipients using plant transformation technology, thereby potentially increasing the disease resistance germ plasm available. Functional transfer of $R$ genes between species requires that the transferred $\mathrm{R}$ product interacts appropriately with heterologous host cell signaling molecules and recognizes a pathogen infecting the new host species. The closer the evolutionary relationship between donor and recipient species, and the pathogens affecting these species, presumably the greater the likelihood of success.

Corresponding author: M. A. Ayliffe; E-mail: michael.ayliffe@csiro.au M. A. Ayliffe and M. Steinau made equal contributions to this work.
A number of examples of functional $R$ gene transfer between solanaceous species have been reported using nucleotide binding site leucine-rich repeat (NBS-LRR) genes, extracellular LRR genes, and protein kinase $R$ genes (HammondKosack et al. 1998; Rommens et al. 1995; Tai et al. 1999; Thilmony et al. 1995; Whitham et al. 1996). The $B s 2$ gene from pepper has been shown to activate a defense response in a number of solanaceous species but not in nonsolanaceous hosts, suggesting that, in some cases, functional $R$ gene transfer may be limited to members of the same family (Tai et al. 1999). Conversely, the RPW8 genes from Arabidopsis spp. have been shown to provide resistance against Erysiphe and Oidium spp. in both Nicotiana tabacum and N. benthamiana, demonstrating functional interfamily transfer of these $R$ genes (Xiao et al. 2003a). Similarly, the tomato $C f 9$ gene can activate a defense response in Brassica spp. in the presence of the corresponding avr9 product (Hennin et al. 2001). The only example of functional $R$ gene transfer between sexually incompatible cereal species was demonstrated by transient assay, whereby the barley Mla6 gene enhanced a nonhost resistance response in wheat to Blumeria graminis f. sp hordei containing the corresponding AvrMla6 gene (Halterman et al. 2001).

These experiments confirm that $R$ genes can activate a defense response in related host species. However, in these examples, either the corresponding avirulence ligand was provided artificially or pathogen races capable of infecting both donor and recipient species were used. Therefore, host signal transduction molecules are conserved among nonsexually compatible plants species in some cases, but the ability of heterologous $R$ genes to recognize pathogen species not currently encountered is unclear.

Here we use the maize $R p l-D$ gene to investigate its potential against related pathogens in transgenic wheat and barley. The Rpl complex of maize consists of a tightly linked family of NBS-LRR genes on the short arm of chromosome 10 (Collins et al. 1999). Different $R p l$ genes control resistance to different biotypes of Puccinia sorghi, which causes common leaf rust of maize (Hooker 1985, Richter et al. 1995). Most Rpl genes confer no detectable resistance phenotype, but genes conferring over a dozen different race specificities are known to exist. The best characterized haplotype, $h R p 1-D$, consists of nine different family members, including the $R p l-D$ gene (Collins et al. 1999; Sun et al. 2001). Homologs of this maize rust resistance gene family have been identified in a range of cereal species, including wheat and barley (Ayliffe et al. 2000).

The ability to utilize maize rust resistance genes in heterologous species could greatly impact efforts to control cereal 
rusts, particularly in the small grains like wheat and barley where rust diseases can significantly reduce production. Successful utilization of race-specific $R p l$ genes in wheat or barley also is likely to depend upon pathogen genotypes. The Puccinia spp. that cause rust diseases of wheat and barley do not cause disease on maize; therefore, it is not possible to determine if they carry an Avr gene corresponding to any of the race-specific $R p l$ genes. Race-specific $R p l$ genes would not be expected to provide resistance to rust pathogen species that did not express an equivalent $a v r R p 1$ gene. However, infection of maize with wheat and barley rust pathogens results in a nonhost hypersensitive resistance response, which may be mediated, in part, through recognition by $R p l$ genes.

The aim of this study was to determine whether the maize $R p 1-D$ rust resistance gene can function in wheat or barley and provide protection against isolates of $P$. graminis f. sp. tritici (causal agent of stem rust of wheat and barley), $P$. triticina (causal agent of leaf rust of wheat), and $P$. hordei (causal agent of leaf rust of barley) or give an altered nonhost response in these species upon infection with $P$. sorghi. In this article, we

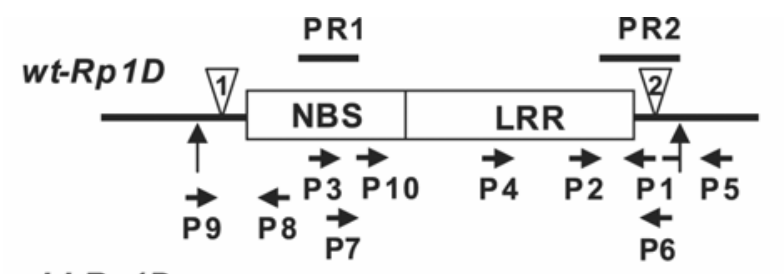

ubi-Rp1D
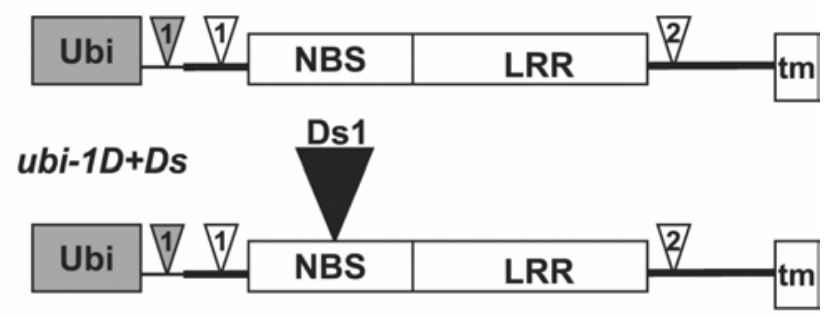

act-Rp1D



psk300

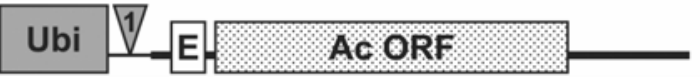

Fig. 1. Gene constructs used for maize, barley, and wheat transformation. The maize $R p 1-D$ gene is shown as white rectangle with the nucleotide binding site (NBS) and leucine-rich repeat (LRR) regions indicated. The $5^{\prime}$ and $3^{\prime}$ flanking regions of the gene are shown as a dark line with intron 1 and intron 2 of the gene drawn as triangles labeled 1 and 2, respectively. The 1.28-kb 3' end used in all Rpl-D constructs encompassed all known polyadenylation sites, which are located approximately $330 \mathrm{bp} 3^{\prime}$ of the translation stop codon. Vertical arrows show transcription start and polyadenylation sites, while horizontal lines labeled PR1 and PR2 indicate probes used for nucleic acid hybridizations. Annealing sites of primers P1 to P10 are shown as small arrows. Primer P1 flanks intron 2 of the gene and, therefore, is shown as a broken arrow. For other constructs, the maize polyubiquitin promoter (gray box), $5^{\prime}$ untranslated region (thin line), and first intron (gray triangle labeled 1) are shown, and the rice actin promoter equivalent is shown as hatched symbols. The Ds 1 element inserted into the open reading frame (ORF) of $u b i-1 D+D s$ is shown as a black triangle. In some constructs, a $3^{\prime}$ transcription termination sequence from the Agrobacterium tumor morphology 1 gene was included and is labeled tm. Construct $p s k 300$ encodes an Ac transposase gene (spotted box) regulated by a maize polyubiquitin promoter and contains an omega transcriptional enhancer (E) in the leader sequence (Upadhyaya et al. 2002). describe expression of this gene in these two heterologous cereal hosts.

\section{RESULTS}

\section{Demonstration of $R p 1-D$ resistance gene function in transgenic maize.}

The $R p l-D$ resistance gene previously was cloned by transposon tagging using both $\mathrm{Ac}$ and $\mathrm{Mu}$ transposable element mutagenesis (Collins et al. 1999). A full-length clone of this gene was generated containing $1.2 \mathrm{kbp}$ of sequence $5^{\prime}$ of the translation initiation site and $1.28 \mathrm{kbp} 3^{\prime}$ of the translation termination site of the Rpl-D open reading frame (ORF) (Fig. 1, $w t-R p 1 D)$. Rpl-D transcript polyadenylation occurs at a site 329 bp $3^{\prime}$ of the translation stop codon, with a potential polyadenylation signal sequence located $30 \mathrm{bp} 5^{\prime}$ of this polyadenylation site (see sequence accession AF107293). Two additional transcript polyadenylation sites subsequently have been identified $15 \mathrm{bp} 5^{\prime}$ and $40 \mathrm{bp} 3^{\prime}$ of this first site (unpublished data). Therefore, the $1.28 \mathrm{kbp}$ of sequence $3^{\prime}$ of the $R p 1-D$ translation stop codon is likely to encompass all $3^{\prime}$ regulatory sequences required for correct transcription termination and mRNA processing of $R p 1-D$ transcripts. A second $R p 1-D$ transgene was generated which included the first 362 bp of transcribed sequence $5^{\prime}$ of the $R p-1 D$ translation initiation site fused to a maize polyubiquitin gene promoter and $1.28 \mathrm{kbp} 3^{\prime}$ of the translation termination site followed by a tml terminator (Fig. 1, construct $u b i-R p 1 D$ ). Maize line Hill was transformed with both constructs and 12 independent lines generated containing $w t-R p l D$ and 11 lines containing the $u b i-R p l D$ construct (Table 1 ).

T0 plants containing either construct were infected with $P$. sorghi isolate IN1, a rust isolate that is virulent on line Hill but avirulent on maize lines containing the $R p l-D$ resistance gene. One $w t-R p 1 D$ line, wt-16A, and one $u b i-R p 1 D$ line, ubi-10A, were resistant to this rust isolate when compared with nontransformed HiII plants (Table 1). T0 plants also were tested with a second $P$. sorghi isolate, HII, which is virulent on maize plants containing the Rpl-D resistance gene. Both transgenic lines were fully susceptible to this second rust isolate, demonstrating that the Rpl-D resistance specificity is encoded by both transgenes. DNA blot analysis of these resistant lines showed that they contained two and nine transgene copies, respectively (data not shown). Transgenic lines that still showed susceptibility had transgene copy numbers varying from one to nine.

The rust-resistant phenotype conferred by transgenes in both wt-16A and ubi-10A lines was shown to be stably inherited and indistinguishable from the original $R p 1-D$ specificity. These two resistant transgenic lines initially were crossed to the susceptible maize line HiII and then crossed several times to maize line H95, which is susceptible to all isolates of maize rust used in this study. Progeny from advanced generations were infected with maize rusts IN1 and IN3, which each carry the avrRpl-D avirulence gene. Among these families, plants that contained either the $w t-R p 1 D$ or $u b i-R p 1 D$ transgene (as determined by DNA blot analysis) showed a resistance phenotype that was indistinguishable from that observed for a maize line heterozygous for the endogenous Rpl-D haplotype in a H95 background and indistinguishable from each other (Fig. 2).

$R p 1-D$ transcripts were compared in these transgenic lines by reverse-transcription polymerase chain reaction (RT-PCR). As an internal RT-PCR control, primers that amplify transcripts from the unrelated $R p 3$ resistance gene family were included. The amount of transcript detected in resistant seedlings from the wt-16A and ubi-10A lines appeared similar to the level of $R p l-D$ transcript observed for the native $R p l-D$ 
haplotype (Fig. 3A). This similarity was verified further by quantitative RT-PCR analysis (Fig. 3B). The data presented from $R p 1-D$ transgenic maize demonstrate that the race-specific resistance to $P$. sorghi conferred by $R p 1-D$ could be transferred as a single gene.

\section{The $w t-R p 1 D$ transgene does not confer rust resistance in wheat and barley.}

The above maize transformation experiments show unambiguously that $w t-R p 1 D$ encodes a fully functional $R p 1-D$ gene when introduced into maize. This construct was introduced into both wheat and barley. In all, 43 independent transgenic wheat lines containing $w t-R p l D$ were generated by biolistic transformation of cvs. Bobwhite, Fielder, B206, Aka, and Opata with $25,9,6,2$, and 1 transgenic lines generated for each cultivar, respectively (Table 1). Transgene presence was confirmed in these lines by DNA blot analysis (data not shown).

T1 families of Fielder, B206, Aka, and Opata and 16 of the Bobwhite lines were challenged with $P$. graminis f. sp. tritici pathotypes 343-1,2,3,5,6 and 98-1,2,3,5,6, which are virulent on the above cultivars. Combined, these two strains of wheat rust contain 15 different known avirulence genes that are recognized by wheat resistance genes. No infection reaction differences were observed between nontransformed lines and wheat lines containing the $w t-R p 1 D$ transgene, regardless of the genetic background. The remaining nine Bobwhite lines were challenged with $P$. triticina isolates $\mathrm{mcrl}$ and $\mathrm{mcrc}$. Again, no altered phenotype was conferred by the $w t-R p 1 D$ transgene (Table 1).

The $w t-R p 1 D$ transgene was introduced into barley cv. Golden Promise by Agrobacterium sp.-mediated transformation. Thirty-six lines were generated that were shown to contain at least one copy of the transgene by DNA blot analysis (Table 1). T1 families of all 36 barley lines were challenged with seven isolates of $P$. graminis and a single isolate of $P$. hordei, all of which are virulent on Golden Promise barley. Combined, these rust isolates contain 20 known stem rust avirulence genes and seven known leaf rust avirulence genes. No difference in infection response was observed between transgenic lines and untransformed control plants (Table 1).

Infection of wheat and barley with $P$. sorghi results in a nonhost resistance response with hypersensitive resistance flecks.
Two T4 Bobwhite wheat lines and four T2 barley lines homozygous for a single copy of $w t-R p 1 D$, all of which had been shown to express the $R p 1-D$ transgene by RT-PCR (see below), were challenged with a $P$. sorghi isolate containing the corresponding avrRpl-D gene. No difference in nonhost response was observed between transgenic lines and untransformed plants at either a macroscopic or microscopic level.

\section{Low levels of transcript detected in $w t-R p 1 D$ wheat and barley lines.}

Transcriptional analysis of $w t-R p l D$ barley and wheat lines was undertaken by both RT-PCR and RNA blot analysis. No phenotypic difference was observed in any transgenic plants; therefore, a randomly selected subsample was used to examine transgene expression levels. In RNA from eight independent T0 barley lines and RNA from progeny of six independent transgenic Fielder wheat lines, no wt-RplD transcripts could be detected by RNA blot analysis using a probe (Fig. 1, probe PR1) specific for the NBS region of the gene (Table 1). RNA blot analyses of a subset of these lines are shown in Figure 4A and B. However, in an equivalent loading of total RNA from a maize line homozygous for the $R p l-D$ haplotype, two transcript classes were clearly identified (Fig. 4A and 4B). A 4-kb band was observed that consisted of transcripts encoding a full-length Rp1-D protein in addition to comigrating transcripts derived from six other members of the Rpl-D haplotype (Sun et al. 2001). A second 2-kb transcript was observed derived from the gene rpl-Cin4, which is also a member of this haplotype (Collins et al. 1999). The rpl-Cin4 gene consists of the NBS and $5^{\prime}$ untranslated region of an Rpl-D paralogue fused to a retrotransposable element sequence. The chimeric gene generates a $2-\mathrm{kb}$ transcript consisting of 1,599 bp of an rpl gene member and 475 bp of retrotransposable element sequence and encodes the first 466 amino acids of an rpl-like protein fused to 21 amino acids of retrotransposable element sequence (Collins et al. 1999).

When these $w t-R p 1 D$ Fielder wheat and barley RNAs were hybridized with a probe from the 3' LRR region of Rpl-D (Fig 1 , probe PR2) no homologous transcripts were identified in these samples, whereas 4-kb $R p l$ transcripts clearly were identified in RNA from a nontransgenic $h R p l-D$ control maize line (data not shown) (Table 1).

Table 1. Summary of rust pathogenicity testing and molecular analyses of transgenic plants

\begin{tabular}{|c|c|c|c|c|c|}
\hline Species/cultivar & Construct & No. of transgenic lines & No. of rust-resistant lines & RNA blot PR1 (PR2) & RT-PCR $^{\text {b }}$ \\
\hline \multicolumn{6}{|l|}{ Maize } \\
\hline HiII & $w t-R p 1 D$ & 12 & $1 / 12$ & $\mathrm{ND}^{\mathrm{c}}$ & $6 / 6^{\mathrm{d}}$ \\
\hline HiII & $u b i-R p 1 D$ & 11 & $1 / 11$ & ND & $6 / 6^{\mathrm{d}}$ \\
\hline \multicolumn{6}{|l|}{ Wheat } \\
\hline Bobwhite & $u b i-R p 1 D$ & 6 & $0 / 6$ & ND & $2 / 6^{\mathrm{e}}$ \\
\hline Bobwhite & $w t-R p 1 D$ & 25 & $0 / 25$ & ND & $2 / 9^{\mathrm{e}}$ \\
\hline Fielder & $w t-R p 1 D$ & 9 & $0 / 9$ & $0 / 6(0 / 6)$ & $6 / 6^{\mathrm{f}}$ \\
\hline B206 & $w t-R p 1 D$ & 6 & $0 / 6$ & ND & ND \\
\hline Aka & $w t-R p 1 D$ & 2 & $0 / 2$ & ND & ND \\
\hline Opata & $w t-R p 1 D$ & 1 & $0 / 1$ & ND & ND \\
\hline \multicolumn{6}{|l|}{ Barley } \\
\hline Golden Promise & $w t-R p 1 D$ & 36 & $0 / 36$ & $0 / 8(0 / 8)$ & $7 / 8^{f}$ \\
\hline Golden Promise & act-Rp1D & 10 & $0 / 10$ & $5 / 7(0 / 7)$ & $9 / 10^{f}$ \\
\hline \multirow[t]{2}{*}{ Golden Promise } & $u b i-1 D+D s$ & 30 & $0 / 4$ & $4 / 4(0 / 4)^{\mathrm{g}}$ & $2 / 2^{\mathrm{g}, \mathrm{h}}$ \\
\hline & & & & $8 / 8$ (ND) & ND \\
\hline
\end{tabular}

\footnotetext{
${ }^{a}$ Number of lines in which transcripts were detected by RNA blot. Results obtained with probe PR1 and probe PR2 are shown, with the latter in parentheses.

${ }^{b}$ Number of lines in which transcripts were detected by reverse-transcription polymerase chain reaction.

${ }^{\mathrm{c}} \mathrm{ND}=$ not done.

${ }^{\mathrm{d}}$ Resistant progeny from wt-16A and ubi-10A tested with primers P4 and P5.

e Detection using primers P2 and P6.

${ }^{\mathrm{f}}$ Detection using primers $\mathrm{P} 1$ and $\mathrm{P} 2$.

${ }^{g}$ Indicates sibs tested rather than independent transgenic lines.

${ }^{\mathrm{h}}$ Detection using primers polydT and $\mathrm{P} 3$ or $\mathrm{P} 7$.
} 
RT-PCR was undertaken on the same $w t-R p 1 D$ Fielder progeny RNAs in addition to RNA from nine T0 wt-RplD Bobwhite lines. Primer P6 was used for reverse transcription and primers $\mathrm{P} 1+\mathrm{P} 2$ and $\mathrm{P} 2+\mathrm{P} 6$ were used for PCR amplification of Fielder and Bobwhite first-strand cDNAs, respectively. These primers target the $3^{\prime}$ region of $R p 1-D$ that is homologous to probe PR2 (Fig. 1). RT-PCR products were amplified from two of the nine Bobwhite RNAs and also amplified from some progeny RNAs of all six Fielder lines (Fig. 4A; Table 1). A similar RT-PCR analysis using primers P1+ P2 (Fig. 1) was undertaken on RNA from the eight T0 $w t-R p 1 D$ barley lines for which no Rpl-D transcripts could be identified by RNA blot analysis. RT-PCR amplification products were amplified from seven of these barley lines (Table 1).

These data show that only a very low level of $R p l-D$ transcript is present in wheat and barley lines containing $w t-R p 1 D$ when compared with the endogenous maize $R p l-D$ gene. These barley and wheat transcripts cannot be detected by RNA blot using either a $5^{\prime}$ - or $3^{\prime}$-specific probe. However, RT-PCR products were amplified from the $3^{\prime}$ end of $w t-R p 1 D$ transcripts in wheat and barley lines, suggesting a low level of $3^{\prime}$ encoding transcripts that are beyond the limit of RNA blot detection.

\section{Attempted overexpression of the Rp1-D gene}

in wheat and barley produces truncated transcripts.

A possible explanation for the apparently low level of $R p 1$ $D$ transcript present in $w t-R p l D$ wheat and barley lines is an inability of maize $R p 1-D$ transcriptional regulatory sequences to function in these heterologous hosts. To test this hypothesis, transgenic wheat and barley lines were generated containing

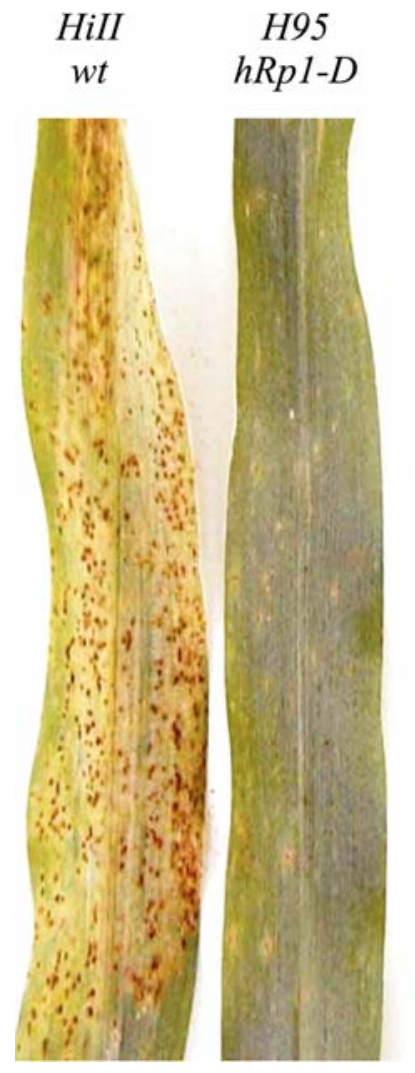

$w t-$

\section{$16 \mathrm{~A}$}

$u b i-$

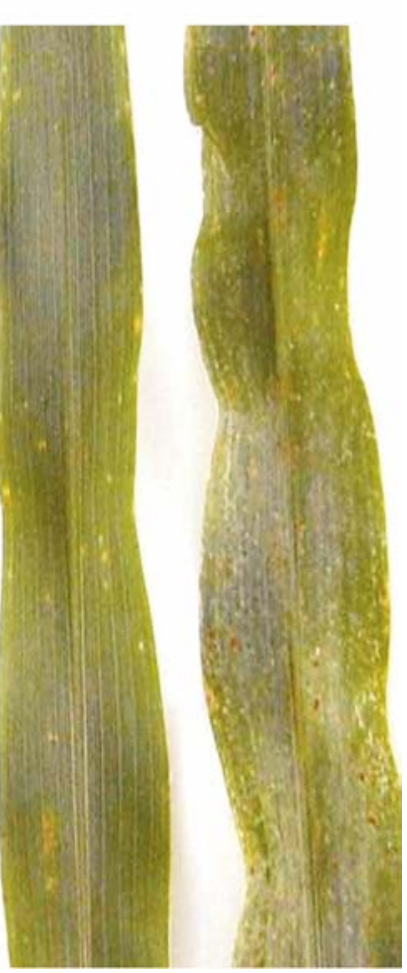

Fig. 2. Rust infection phenotypes on the fourth leaf of transgenic maize seedlings 7 days after inoculation with Puccinia sorghi isolate IN1. From left to right: fully susceptible nontransgenic maize (HiII), a nontransgenic $h R p 1-D$ heterozygote in the $\mathrm{H} 95$ background showing a hypersensitive resistance phenotype, transgenic line wt-16A showing a hypersensitive resistance phenotype, and the resistance phenotype of ubi-10A.
Rpl-D transgenes controlled by strong, constitutive promoters known to function in both these cereal species. Six Bobwhite wheat lines were generated containing the $u b i-R p 1 D$ transgene previously shown to function in maize. Transgene expression was identified in two of these wheat lines by RT-PCR using primers P2 and P6 (Fig. 1; Table 1). Ten barley lines were generated containing the $R p l-D$ gene under the control of a rice actin promoter (Fig. 1, act-RplD) and Rpl-D RT-PCR amplification products were obtained from nine of these lines using primers P1 and P2 (Fig. 1; Table 1). Rust testing of subsequent generations of these transgenic cereals with the above rust isolates showed no differential response to rust infection between transgenic and nontransgenic control lines.

Total RNA was isolated from barley lines containing act$R p 1 D$ and hybridized with a probe (Fig. 1, probe PR1) homologous to the NBS region of the Rpl-D gene (Fig. 4C). A control maize line homozygous for an endogenous $R p 1-D$ haplotype showed the two expected transcript types, a 4-kbp class containing transcripts from the $R p 1-D$ gene and related family members, and 2-kbp transcripts from the rpl-Cin4 gene (Fig. 4C). However, in RNAs from act-RplD barley lines, the only transcripts identified by RNA blot analysis with homology to the 5' Rpl-D probe were approximately $2 \mathrm{kbp}$ in length. No equivalent transcripts were present in RNA from untransformed barley plants, confirming that these small transcripts are the products of act-Rp1D expression (Fig. 4C). The expression level of these small transcripts was lower than that observed for the maize $R p 1$ genes and, hence, much lower than that expected for the strong, constitutive actl promoter. No evidence of a full-length $R p 1-D$ transcript was detected in any barley line by overexposure of RNA blots (data not shown).

RNA samples were rehybridized with a probe specific for the 3' LRR region of the Rpl-D gene (Fig. 1, PR2). A 4-kbp transcript class was observed in control maize RNA consistent with the LRR region of the gene being present in full-length

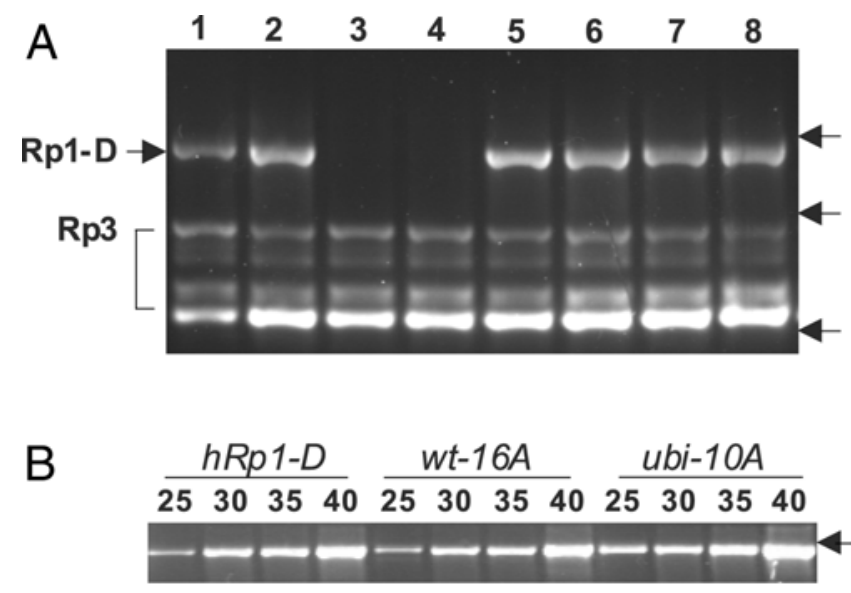

Fig. 3. Reverse-transcription polymerase chain reaction (RT-PCR) expression analysis of the $R p 1-D$ gene in transgenic and nontransgenic maize. A, $R p 1-D$ specific primers (P4 and P5) were used to amplify a 1.5$\mathrm{kb}$ cDNA fragment in multiplex RT-PCR reactions with primers F1 and NBSR1 that amplify Rp3 gene family transcripts (880 bp and smaller). Products were amplified from total RNA of wild-type maize seedlings homozygous for the $h R p 1 D$ haplotype (lanes 1 and 2), seedlings from the rust-susceptible (HiII) line used as a recipient for the transgenes (lanes 3 and 4), resistant wt-16A seedlings (lanes 5 and 6), and resistant ubi-10A seedlings (lanes 7 and 8). Arrows on the right side of the figure indicate molecular weights of 1,636, 1,018, and $506 \mathrm{bp}$, respectively. B, Quantitative RT-PCR of total RNA extracted from wild-type maize seedlings containing the $h R p l-D$ haplotype, resistant wt-16A seedlings, and resistant ubi-10A seedlings. RNAs were RT-PCR amplified with primers P4 and P5 for 25, 30, 35, and 40 cycles, respectively. The arrow on the right side of the figure indicates a molecular weight of 1,636 bp. 
Rpl transcripts, but absent in rpl-Cin4 transcripts (Fig. 4D). Several other smaller, minor maize bands also were observed with homology to this probe. No homologous sequences were identified in RNA from act-RplD barley lines or untransformed barley plants (Fig. 4D). These data suggest that the 2kbp transcripts present in these transgenic barley lines are truncated and do not encode the LRR region of the act-RplD transgene. In contrast, RT-PCR analysis did detect transcripts encoding $3^{\prime}$ regions of the $R p l-D$ gene in most of these lines, which suggests that the $3^{\prime}$ encoding transcripts also present in these RNAs are of low abundance (Table 1).

To further confirm the relative paucity of $R p l-D$ transcripts encoding the $3^{\prime}$ LRR region in act-RplD barley lines, additional RT-PCR analysis was undertaken. Total RNAs from two act-RplD lines (corresponding to RNAs shown in Fig. 4C and $\mathrm{D}$, lanes 7 and 8) were both reverse transcribed using primers P8 and P6 and PCR amplified with primers P8 + P9 and P2 + P6, respectively (Fig. 1). These primer combinations target the $5^{\prime}$ and $3^{\prime}$ end of the Rpl-D transgene, respectively. Both primer combinations can amplify contaminating genomic
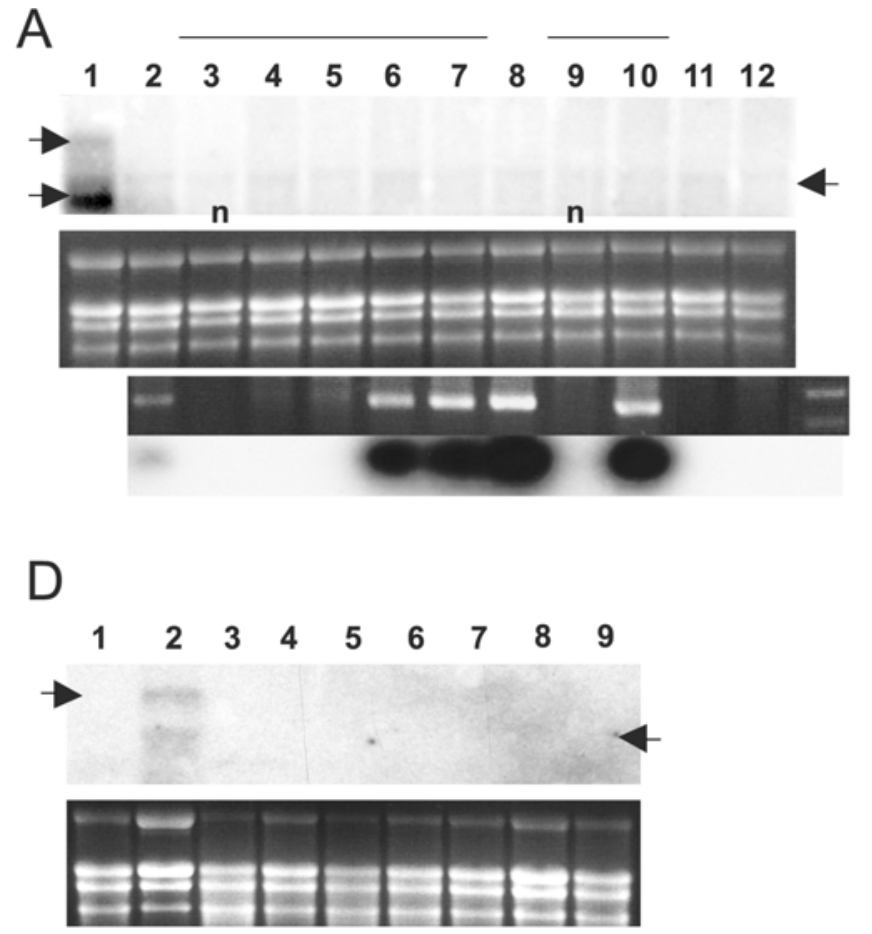

Fig. 4. Transcriptional analyses of wheat and barley lines containing $R p 1-D$ transgenes. A, Hybridization of probe PR1 to total RNA from; wild-type, $h R p 1-$ $D$ homozygous maize (lane 1), progeny from four independent transgenic Fielder wheat lines containing $w t-R p 1 D$ (lanes $2-10$ ) and untransformed Fielder control lines (lanes 11-12). RNAs in lanes 2, 3-7, 8, and 9-10 were isolated from progeny of different independent transgenic parents and each family is grouped accordingly with lines above the figure. RNAs in lanes 3 and 9 marked with an " $n$ " beneath the panel are from progeny that did not inherit parental $w t-R p 1 D$ transgenes and serve as additional negative controls. RNAs in lanes 4 and 5 were from progeny that inherited two transgene loci while RNAs in lanes 6 and 7 were from sibs of the same family that had inherited four transgene loci, at least one of which is transcriptionally active (see RT-PCR analysis below). The ethidium bromide-stained gel used for RNA transfer is shown below. Beneath this RNA gel are the reverse-transcription polymerase chain reaction (RT-PCR) products amplified from each RNA sample using primer P6 for reverse transcription and primers P1 + P2 for PCR amplification. The last lane in this panel shows molecular weight markers of 480 and $360 \mathrm{bp}$. These PCR products subsequently were hybridized with probe PR2, shown beneath. Homologous PCR products were detected only in lanes $2,6,7,8$, and 10 , even after a longer exposure than is shown. B, RNA blot of wild-type, $h R p 1-D$ homozygous maize (lanes 1-2), three independent $w t-R p 1 D$ transgenic barley lines (lanes 3-5), and two untransformed Golden Promise barley control lines (lanes 6 through 7), hybridized with probe PR1. The ethidium bromide-stained gel used for RNA transfer is shown on the right side. C, RNA blot of total RNA from transgenic barley lines containing act-RplD (lanes 3 through 9) hybridized with probe PR1. RNA from a maize line homozygous for $h R p 1 D$ is shown in lane 2 and RNA from untransformed Golden Promise barley is in lane 1. The ethidium bromide-stained RNA gel used for transfer is shown below. D, The same RNA samples shown in C hybridized with a probe specific for the leucine-rich repeat region of $R p 1-D$. E, RT-PCR analysis of $a c t-R p 1 D$ lines. Lanes 1 and 2 show 5' Rp-1D RT-PCR amplification products obtained from two act-Rp1D barley RNAs (corresponding to RNAs shown in C and D, lanes 7 and 8) following reverse transcription with primer P8 and PCR amplification with primers P8 + P9. Lanes 3 and 4 show the amplification products obtained from the same RNAs in the absence of reverse transcription, while lane 5 is a control reaction containing no barley nucleic acids. Lanes 6 and 7 contain the 3' Rpl-D RT-PCR amplification products from the same RNA samples used in lanes 1 and 2, respectively, following reverse transcription with primer P6 and PCR amplification with primers P2 + P6. Lanes 8 and 9 contain the amplification products obtained from these two RNAs in the absence of reverse transcription using primers $\mathrm{P} 2+\mathrm{P} 6$, while lane 10 is a control reaction containing no barley nucleic acids. Lane M shows molecular weight sizes of 980, 720, 480, and $360 \mathrm{bp}$. In panels A through D, 4- and 2-kb maize Rpl transcripts are marked with arrows on the left side of figures, while the arrows on the right indicate the position of the $28 \mathrm{~S}$ rRNA band. 
the presence of these products in no reverse transcription control reactions (Fig. 4E). The relative stochiometry of these amplification products did not change with fewer amplification cycles (data not shown). Therefore, both RT-PCR and RNA blot analyses are consistent with a higher abundance of $5^{\prime}$ encoding truncated $R p l-D$ transcripts in act$R p 1 D$ barley RNAs.

Truncated mRNAs are not a consequence of gene function.

A number of reports have shown that overexpression of some $R$ genes can activate a defense response in the absence of pathogen challenge (Bendahmane et al. 2002; Oldroyd and Staskawicz 1998; Stokes et al. 2002; Tang et al. 1999; Tao et al. 2000; Xiao et al. 2001; Xiao et al. 2003a,b). Generation of high-expression wheat and barley lines would not be possible if a high level of $R p l-D$ expression results in a constitutive hypersensitive response. Therefore, the aberrant transgene expression apparent in $a c t-R p 1 D$ barley lines may be a consequence of selection during plant regeneration for the lack of expression of a functional Rp1-D protein. To investigate this possibility, 30 barley lines were generated containing a $u b i-R p 1 D$ construct disrupted with a maize $D s 1$ transposable element (Fig. 1, ubi-1D+Ds) (Table 1). The insertion of $D s l$ in this gene location is known to prevent expression of a functional Rp1-D protein in maize, because it was this insertionally inactivated form of the gene that was recovered from transposon mutagenesis experiments (Collins et al. 1999).

No altered phenotype was observed in barley lines containing $u b i-1 D+D s$. To determine if excision of the $D s 1$ element could generate an overexpression phenotype, these lines were crossed to barley lines expressing Ac transposase (Fig. 1, psk300) (Upadhyaya et al. 2002). Nine $u b i-1 D+D s$ lines were crossed to transposase lines and the resultant progeny examined for sterility, seedling lethality, or a sectored, overexpression phenotype. No such phenotypes were observed.

Progeny from two plants hemizygous for each transgene were characterized by DNA blot analysis. In one family, three sibs showed excision of $D s 1$ as evident by a size reduction in a $B g l I I$ restriction fragment encompassing $D s l$ and part of the Rpl-D NBS region (Fig. 5A and B). Hybridization with a $D s 1$ probe confirmed Dsl excision and showed that, in two sibs, Ds 1 had reinserted elsewhere in the genome (Fig. 5C). A sin-
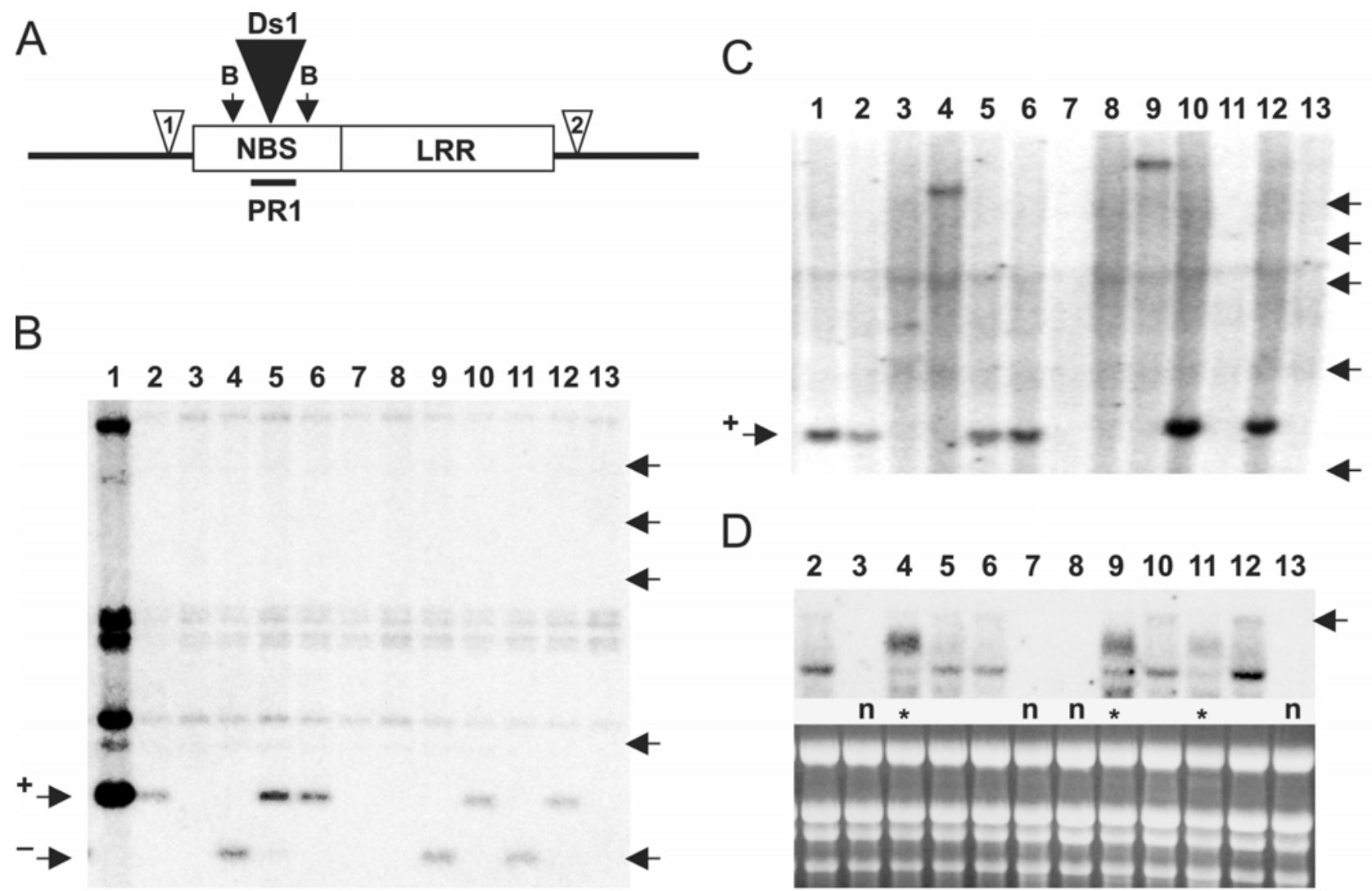

Fig. 5. Molecular analysis of $u b i-1 D+D$ s excision lines. A, Diagram showing part of the $u b i-1 D+D s$ transgene. The insertion site of the $D s 1$ element is shown as a black triangle and BglII restriction sites marked with arrows labeled B. The relative position of probe 1 (PR1) is indicated. B, DNA blot analysis of progeny derived from a plant containing both $u b i-1 D+D s$ and an Ac transposase gene (psk300). DNAs were digested with BglII and hybridized with probe PR1 (see A) which encompasses a region of the nucleotide binding site (NBS). Lane 1 contains parental DNA while the remaining 12 lanes contain DNAs of progeny derived from self-fertilization of the parental line. Hybridization intensities reflect DNA loadings. The Ds 1 containing BglII restriction fragment is indicated with an arrow on the left side of the figure labeled " + ". A reduction in BglII fragment size as a result of $D s 1$ excision can be seen in lanes 4, 9, and 11 (arrow labeled "-"). DNAs in lanes 3, 7, 8, and 13 are derived from progeny that that did not inherit $u b i-1 D+D s$. The remaining hybridizing bands represent endogenous barley homologues of the maize $R p 1-D$ gene (Ayliffe et al. 2000). Arrows on the right side of the figure indicate molecular weights of $8.5,6.1,4.8,2.8$, and $1.95 \mathrm{~kb}$, respectively. C, DNAs shown in B were restricted with $B g l I I$ and hybridized with a probe homologous to the $D s 1$ sequence only. Plants containing an unexcised $D s 1$ element show hybridization to the same $B g l I I$ restriction fragment present in B (marked with an arrow on the left side labeled "+"). Lanes 4 and 9 show new Ds 1 insertions, while lane 11 shows complete loss of the Ds 1 element. Arrows on the right side of the figure indicate molecular weights of 8.5, 6.1, 4.8, 2.8, and 1.95 kb, respectively. D, Hybridization of total RNA from progeny shown in B and C with probe PR1. Plant RNAs in lanes 2 through 13 correspond to plant DNA samples in lanes 2 through 13 of B and C. RNAs from plants in which Ds 1 had excised are marked with an asterisk below the lane, while progeny not inheriting the $u b i-1 D+D s$ transgene are labeled "n". The ethidium bromide-stained RNA gel used for transfer is shown beneath. An arrow on the right side of the figure indicates the position of the $28 \mathrm{~S}$ rRNA band. 
gle plant showing Dsl excision was identified in the second family (data not shown). None of these four plants showed resistance when challenged with rust (Table 1). PCR amplification and sequence analysis of the $R p l-D$ gene in these four plants showed that, in two cases, Dsl had excised without leaving a footprint, thereby maintaining a functional $R p l-D$ ORF. As a consequence of this excision event, the transgene contained in these two barley plants is identical in sequence to the $u b i-R p 1 D$ transgene that was introduced into both wheat and maize. For the remaining two plants, a small sequence duplication characteristic of $D s 1$ excision was apparent that potentially could inactivate the gene (data not shown).

RNA blot analysis of $u b i-1 D+D s$ lines and lines in which the $D s 1$ element had perfectly excised to maintain a fully func-
A

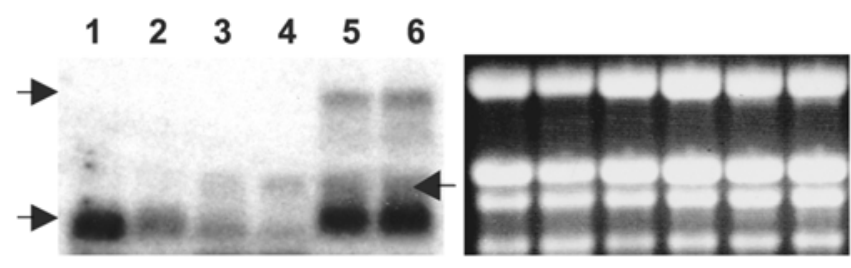

C

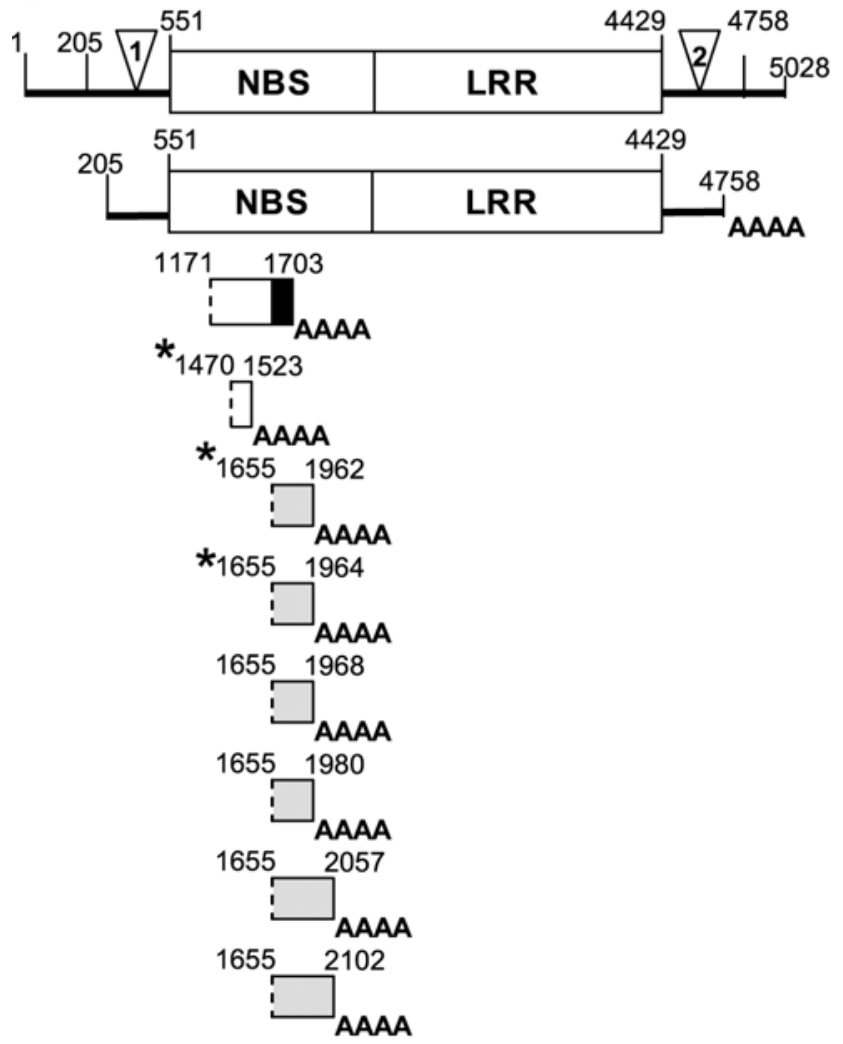

B

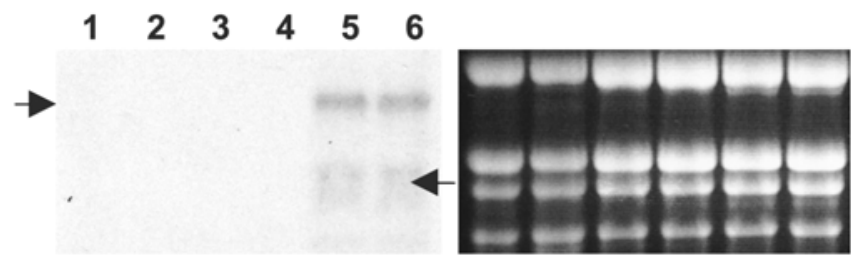

D

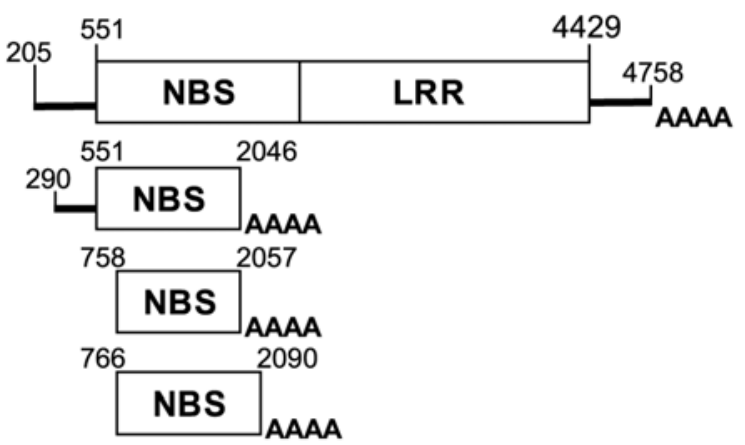

Fig. 6. Expression analysis of $u b i-1 D+D s$ barley lines. A, RNA blot analysis of $u b i-1 D+D s$ lines. Total RNA extracted from four progeny derived from a plant containing both $u b i-1 D+D s$ and an Ac transposase gene (psk300) was hybridized with probe PR1. Lanes 1 and 2 contain RNA from plants in which $D s 1$ excision had occurred to restore a functional $R p 1-D$ open reading frame (ORF) while lanes 3 and 4 contain RNA from sibling plants in which $D s 1$ had not excised. Lanes 5 and 6 contain RNA from a maize line homozygous for an endogenous Rpl-D haplotype. Rpl transcripts of 4 and 2 kb are marked with arrows on the left side of the figure, while the arrow on the right side of the autoradiograph indicates the position of the 28S rRNA band. The RNA gel used for transfer is shown on the right side of the figure. B, Hybridization of the RNA samples in A with probe PR2 which encodes part of the Rp1-D leucine-rich repeat (LRR) region. The arrow on the left side of the autoradiograph marks the position of 4-kb Rpl transcripts present in total maize RNA, while the arrow on the right indicates the position of the $28 \mathrm{~S}$ rRNA band. The RNA gel used for transfer is shown on the right side of the figure. C, Reversetranscription polymerase chain reaction (RT-PCR) products obtained from transgenic barley and wheat lines. The upper diagram depicts the published sequence of the endogenous Rpl-D gene (accession number AF107293) with numbers corresponding to nucleotide positions. Shown immediately beneath is the full-length $R p 1-D$ transcript no longer containing introns 1 and 2. To allow direct comparison between genomic and RNA sequences, nucleotide positions on RNA sequences have not been altered to account for intron loss. A depiction of the RT-PCR product obtained from $u b i-1 D+D s$ barley line $1+D s$ RNA is shown third, with the 87-bp $D s 1$ region of this transcript shown as a black box. The RT-PCR product from $u b i-1 D+D s$ barley line 1 is shown fourth. Primer P3 or P7 and a polydT primer were used for RT-PCR amplification of the upper and lower barley product, respectively. RT-PCR products amplified from a $u b i-R p 1 D$ wheat line using primers P10 and polydT are shown as shaded boxes with nucleotide positions indicated. Two clones were isolated for wheat and barley products marked with an asterisk. A dotted line on the left of these PCR products indicates that the $5^{\prime}$ end of the products were defined by PCR primers and the exact starting point of the template transcripts is unknown. D, Truncated, polyadenylated $R p 1-D$ cDNA clones from $h R p 1-D$ maize. The upper diagram shows a full-length $R p 1-D$ transcript with numbers corresponding to nucleotide positions of the $R p 1-D$ genomic sequence (accession number AF107293). The ORF of the gene is illustrated as a rectangle with nucleotide binding site (NBS) and LRR domains indicated and $5^{\prime}$ and $3^{\prime}$ leader sequences shown as black lines. The three diagrams below represent truncated $R p 1-D$ cDNA clones isolated from a maize cDNA library, with nucleotide positions indicated. 
tional ORF also identified 2-kbp transcripts homologous to the NBS region of the $R p l-D$ gene (Fig. 6A). No transcripts homologous to the LRR region of the gene were identified by RNA blot analysis (Fig. 6B). Therefore, the truncated transcripts in these barley lines are not the result of strong selection during regeneration for the lack of expression of a functional protein, because transcripts derived from an insertionally inactive version of the gene also underwent aberrant RNA processing. Transgenes that had this insertion sequence removed in vivo to restore a functional Rpl-D ORF also produced similar truncated transcripts.

A higher-resolution RNA blot, hybridized with probe PR1, identified a spectrum of 1.5 - to $2-\mathrm{kb} R p 1-D$ transcription products in barley lines maintaining $D s 1$ within the $R p 1-D$ ORF that was different when compared with sibling lines in which Dsl had excised, suggesting that multiple aberrant transcript types are produced (Fig. 5D). An absence of hybridizing sequences in RNA from sibling lines null for the $u b i-1 D+D s$ transgene demonstrates that these transcription products are transgene derived (Fig. 5D).

\section{Molecular analysis \\ of truncated transcription products from barley.}

To examine these transcripts further, RT-PCR analysis was undertaken on RNA from a $u b i-1 D+D s$ line (line $1+\mathrm{Ds})$ and a sib line containing the same transgene but which had the Ds1 element perfectly excised by Ac transposase (line1) (DNA and RNA blot analyses of line1+Ds and line1 are shown in Fig. 5, lanes 5 and 9, respectively, and Fig. 6, lanes 3 and 1, respectively). Total RNA was reverse transcribed with a poly dT primer and the resultant first-strand cDNA PCR amplified using the same poly dT primer in conjunction with a primer specific to the NBS region of the Rpl-D gene (Fig. 1, primer P3 or P7). Two identical products were cloned from line1 RNA and encoded the NBS region of $R p l-D$ up to nucleotide 1,523 of the published gene sequence, (accession number AF107293), before being prematurely truncated by polyadenylation (Fig. 6C). A single product was cloned from line1+Ds RNA encoding the $R p l-D$ NBS region up to nucleotide 1,703 of the published gene sequence and then included the first 87 bp of Dsl before polyadenylation (Fig. 6C).

The absence of LRR sequences in these products is consistent with RNA blot analyses and consistent with most transcripts in these lines not encoding a functional Rp1-D protein as a consequence of premature polyadenylation. In addition, these two different product types are consistent with a different spectrum of truncated transcription products being present in $u b i-1 D+D s$ lines compared with sibling lines in which $D s 1$ has excised (Fig. 5D).

\section{Truncated $R p 1-D$ transcripts are generated in $u b i-R p 1 D$ wheat lines.}

To determine whether truncated $R p 1 D$ transcripts are produced in transgenic wheat lines, further RT-PCR analysis was undertaken on RNA from a $u b i-R p 1 D$ transgenic wheat line that previously was shown to express the $R p 1-D$ transgene by RT-PCR using primers P2 and P6 (Fig. 1; Table 1). Total RNA was reverse transcribed with a polyd $\mathrm{T}_{(23)}$ primer and PCR amplified with primer $\mathrm{P} 10$ and polydT $\mathrm{T}_{(23)}$. Sequence analysis of cloned PCR products identified eight clones identical in sequence to the $R p l-D$ transgene and unambiguously derived from truncated and polyadenylated $R p l-D$ transcripts, with each clone possessing a polyA tail varying in size from 24 to $53 \mathrm{bp}$. Four of these clones truncate at unique positions within the NBS encoding domain of the RplD ORF, while the remaining four clones truncate at two unique positions (Fig. 6C). None of these clones encode the LRR region of the Rpl-D transgene.
Truncated transcripts are generated by the endogenous maize $R p 1-D$ gene.

The production of truncated $R p l-D$ transcripts in wheat and barley lines may be a consequence of the heterologous expression of this transgene. To determine whether such transcripts also are generated by the endogenous maize $R p 1-D$ gene, maize cDNA clones were analyzed. Previously, Collins and associates (1999) screened a maize cDNA library constructed from rust-infected leaf RNA to identify full-length $R p l-D$ cDNA clones (as described in Materials and Methods). From this screen, three independent cDNA clones identical in sequence to the $R p 1-D$ gene were identified that were unambiguously derived from truncated and polyadenylated transcripts (Fig. 6D). Truncation of these three clones occurred at three different sites, spread over approximately $50 \mathrm{bp}$ of the $R p 1-D$ sequence (Fig. 6D). One of these maize cDNA clones truncated in exactly the same position as an Rpl-D RT-PCR product isolated from a $u b i-R p 1 D$ wheat line (i.e., nucleotide position 2,057) (Fig. 6C and D). All three maize clones did not contain a full-length $5^{\prime}$ end, which may be due to either incomplete reverse transcription during cDNA synthesis or further transcript alteration.

These data demonstrate that prematurely truncated and polyadenylated transcripts are produced by the endogenous $R p 1-D$ gene and that the point of truncation is variable, as also was observed for $R p 1-D$ transcripts in $u b i-1 D+D s$ barley plants and a $u b i-R p 1 D$ wheat plant. It is possible that some of the minor bands observed in total maize RNA on RNA blots in Figures 4A, B, and C and 6A could represent similar truncated Rpl transcripts. The presence of other small, faint hybridization products with homology to probe PR2 (Figs. 4D and 6B) raises the possibility that $R p l$ transcripts lacking a $5^{\prime}$ region also may be produced, but verification of the existence of such transcripts is difficult given that the process of reverse transcription invariably generates partial cDNA clones that lack 5' sequences.

\section{DISCUSSION}

Transformation of maize with the $R p l-D$ gene regulated by either its endogenous promoter or a maize polyubiquitin promoter conferred $R p l-D$ race-specific rust resistance in plants expressing this gene, further confirming gene identity. Wheat and barley plants containing $R p 1-D$ gene constructs that were shown to function in maize were incapable of recognizing additional wheat or barley rust isolates that collectively contain a large number of avirulence genes recognized by wheat and barley resistance genes.

No transcripts encoding a functional Rp1-D protein were identified at a substantial level in transgenic wheat and barley, regardless of the transcriptional regulatory sequences used to express the gene. Barley lines containing act-RplD and $u b i$ $1 D+D s$, in which $D s 1$ had excised to generate a potentially functional $u b i-R p 1 D$ transgene, produced $5^{\prime}$ encoding, truncated transcripts in sufficient quantities to be detected by RNA blot analysis. Conversely, transcripts encoding 3' Rpl-D sequences could only be detected by RT-PCR in these lines, demonstrating that these latter transcripts are present in an abundance significantly less than that observed for $5^{\prime}$ encoding transcripts and for the endogenous maize $R p l-D$ gene.

From RNA blot analyses, no Rpl-D transcripts with homology to either the $5^{\prime}$ or $3^{\prime}$ end of the gene could be detected in $w t-R p 1 D$ wheat and barley lines, whereas endogenous $R p 1-D$ maize transcripts were clearly identified in the same experiments. However, $3^{\prime}$ encoding transcripts could be detected in these transgenic cereal lines by RT-PCR analysis, again suggestive of a low level of expression. It is unknown if any of 
these rare $3^{\prime}$ encoding transcripts also contained 5' sequences and could encode a full-length $\mathrm{Rp} 1-\mathrm{D}$ protein.

The successful function of an $\mathrm{R}$ protein in a heterologous host requires the protein to recognize a new pathogen species and interact with heterologous signal transduction molecules. In this study, we have not determined conclusively whether the maize Rp1-D protein can fulfill either of these requirements in wheat or barley. The poor and aberrant expression of the Rpl$D$ transgenes in these species, regardless of the regulatory sequences employed, make it possible that a minimum threshold of Rp1-D protein has not been produced in these lines if, in fact, any full-length protein is produced at all. Therefore, the ability of this maize $\mathrm{R}$ protein to interact with signaling apparatuses present in these other grass species and its ability to recognize rust pathogens of wheat and barley remains inconclusively tested.

In some cases, heterologous expression of $R$ genes can have deleterious effects on the host plant, presumably as a consequence of illegitimate activation of a defense response (Frost 1998; Xiao et al. 2003a). Similarly, overexpression of NBSLRR and other endogenous $R$ genes can activate a defense response in the absence of pathogen infection (Bendahmane et al. 2002; Oldroyd and Staskawicz 1998; Stokes et al. 2002; Tang et al. 1999; Tao et al. 2000; Xiao et al. 2001; Xiao et al. $2003 \mathrm{~b}$ ). Inappropriate activation of a defense response potentially could lead to selection of transgenic lines incapable of expressing a functional $\mathrm{R}$ protein. The inability to transcribe significant quantities of mRNA encoding a functional Rp1-D protein in barley does not appear to be a consequence of selection against an illegitimate defense response, because an insertionally inactivated form of the gene $(u b i-1 D+D s)$ also generated aberrantly processed transcripts.

However, it still is possible that a resistance protein inactive in the endogenous host could inappropriately activate a defense response in a heterologous host. For example, mutation in a pathogen recognition domain may prevent $R$ gene function in the endogenous host, but the signal transduction component of the molecule still may be capable of initiating a defense response in a heterologous host in an illegitimate, ligand-independent fashion. This appears unlikely for the $u b i$ $1 D+D s$ gene because $D s 1$ causes a frameshift, resulting in the addition of 16 additional amino acids to the carboxy terminus of the first 384 amino acids of the Rp1-D protein before translation termination occurs. Therefore, translation of a fulllength $u b i-1 D+D s$ transcript would result in a protein very similar to that encoded by the truncated $R p 1-D$ transcripts isolated from $u b i-1 D+D s$ barley lines. These data suggest that aberrant mRNA processing of the $R p 1-D$ gene in barley is not related to gene function.

Truncated $R p 1-D$ transcription products are not unique to barley because they also were identified in a $u b i-R p l D$ wheat line. The occurrence of similar, and in one case identical, truncated $R p l-D$ transcripts in $h R p l-D$ maize demonstrates that alternative processing events also occur in the endogenous host, although not to the possible exclusion of full-length transcripts as was observed in wheat and barley. Transcription termination, cleavage, and polyadenylation signals are not well characterized in plants but multiple cis elements are required in the vicinity of polyadenylation sites (Mogen et al. 1992; Rothnie 1996). There are a number of reports of premature transcription termination inhibiting expression of heterologous transgenes (Chakraborty et al. 2002; Diehn et al. 1998; Haffani et al. 2000; Jarvis et al. 1997). All these studies observed the production of multiple truncated, polyadenylated transcripts, with low mRNA accumulation and no full-length transcript detected in some cases. These examples involved the transfer of genes between very different species which, a priori, may increase the likelihood of processing signals being incorrectly or over recognized. In contrast, the gene transfer in this study has involved donor and recipient species from the same family, the Poaceae, and, in both recipient species, homologues of the Rpl-D gene have been identified (Ayliffe et al. 2000).

In some cases, endogenous genes can utilize premature transcript polyadenylation as a post-transcriptional regulatory mechanism or for the production of protein variants (Quesada et al. 2003; Zhao et al. 1999). NBS-LRR genes often produce transcripts encoding truncated protein products. These transcripts are generated by alternative splicing, gene rearrangements, point mutations, transposable elements, and, in some cases, premature transcript polyadenylation (Anderson et al. 1997; Ayliffe et al. 1999; Gassmann et al. 1999; Lawrence et al. 1995; Leister et al. 1998; Madsen et al. 2003; Meyers et al. 1998; Noel et al. 1999; Parker et al. 1997; Whitham et al. 1994). In barley, several examples exist where endogenous NBS-LRR genes produce transcripts that are truncated due to premature polyadenylation (Leister et al. 1998; Madsen et al. 2003). Truncation occurs in, or near, the NBS coding region, producing transcription products similar to the $R p l-D$ transcripts present in $a c t-R p 1 D$ and $u b i-1 D+D s$ barley lines, $u b i$ $R p 1 D$ wheat, and the endogenous truncated $R p 1-D$ transcripts present in maize.

For two NBS-LRR genes, transcripts encoding truncated $\mathrm{R}$ proteins have been shown to be essential for function (DineshKumar and Baker 2000; Zhang and Gassmann 2003), although this was not the case for a third gene (Ayliffe et al. 1999). For most $R$ genes, it is unclear whether the potential truncated protein products encoded by these transcripts are essential for resistance, or if these transcripts are either RNA processing artifacts, pseudogene products, or arise from post-transcriptional gene regulation. It is not known whether or not prematurely polyadenylated transcripts generated by the $R p 1-D$ gene in maize are essential for function.

If truncated $\mathrm{R}$ proteins are necessary for resistance, premature transcript polyadenylation is a potential mechanism for generating transcripts encoding such proteins, and this process presumably would involve specific RNA processing signals. Transfer of an $R$ gene to a heterologous host could result in over-recognition of this processing signal, such that a majority of the transcripts were processed into a truncated form. Such a process could account for the truncated $R p 1-D$ transcripts present in transgenic barley and wheat lines, given their occurrence in maize. Alternatively, these transcripts may arise as an RNA processing artifact or a post-transcriptional regulatory process that is more apparent for the $R p 1-D$ sequence in barley and wheat than in maize. Either mechanism does not account for the low transgene expression levels observed in these heterologous cereal hosts, unless aberrant mRNA processing is associated with mRNA instability.

In summary, the maize $R p l-D$ gene does not provide rust resistance in wheat and barley and shows poor gene expression and premature transcript polyadenylation, which may prevent the generation of sufficient quantities of resistance protein.

\section{MATERIALS AND METHODS}

\section{Plant and fungal material.}

Maize line Hill was used in transformation experiments, while line $\mathrm{H} 95$ was crossed with transgenic maize lines. Both lines are susceptible to the isolates of $P$. sorghi used in this study. A line heterozygous for an endogenous $R p 1-D$ haplotype in the $\mathrm{H} 95$ background was used as a positive control for Rp1-D resistance. Wheat cvs. Bobwhite, Fielder, Opata, Aka, and B206 were used for wheat transformation, and cv. Golden Promise was used for barley transformation. 
Transgenic wheat lines were infected with two isolates of $P$. triticina, provided by G. Brown-Guedira, Kansas State University (KSU) (Manhatten, KS, U.S.A.). These isolates were identified at KSU as pathotypes mcrl and $m c r c$, based on the North American system of pathotype nomenclature for this pathogen. Transgenic wheat lines also were tested with $P$. graminis f. sp. tritici pathotypes 343-1,2,3,5,6 (Plant Breeding Institute Cobbitty [PBIC] culture number QWRI343) and 98-1,2,3,5,6 (PBIC culture number 781219). These pathotypes were designated following the system outlined by McIntosh and associates (1995). Pathotype 343-1,2,3,5,6 is virulent for the resistance genes $\operatorname{Sr} 5,6,8 a, 9 b, 11$, and 17 and avirulent on lines containing resistance genes $S r 7 b, 8 b, 9 e, 9 g, 15,21,24,26$, $27,30,31,32,35,36$, and 38 , and pathotype $98-1,2,3,5,6$ is virulent for the resistance genes $\operatorname{Sr} 5,6,8 a, 9 b, 9 g, 11$, and 17 and avirulent on lines containing resistance genes $S r 7 b, 8 b, 9 e$, $15,21,24,26,27,30,31,32,35,36$, and 38 .

Transgenic barley was challenged with $P$. hordei pathotype 4653P+ (PBIC culture number 990492), designated using the octal system as described by Gilmour (1973). This pathotype is virulent on plants containing resistance genes $R p h 1,2,4,6$, $8,9,12,13$, and 19 and avirulent on lines with resistance genes Rph3, 5, 7, 10,11,14, and 15, and was used because it displayed full virulence for Golden Promise. The transgenic barley plants also were inoculated with $P$. graminis $\mathrm{f}$. sp tritici pathotypes 343-1,2,3,5,6; 34-2,12,13 (PBIC culture number 840552); 21-0 (PBIC culture number 540129); 126-5,6,7,11 (PBIC culture number 334), P. graminis $\mathrm{f}$. sp secalis pathotype H34 (PBIC culture number 60-L-1), and two isolates of a form of $P$. graminis regarded to be hybrids between formae speciales tritici and secalis (810633 and 970220). Pathotype 34$2,12,13$ is not recognized by resistance genes $\operatorname{Sr} 5,7 b, 9 g, 11$, and 12 and is avirulent on plants containing resistance genes Sr6, $8 a, 8 b, 9 b, 9 e, 15,17,21,24,26,30,31,32,35,36$, and 38 ; pathotype $21-0$ is virulent on plants with the resistance genes $S r 6,7 b$, and $9 g$ and avirulent on lines with resistance genes $\operatorname{Sr} 5,8 a, 8 b, 9 b, 9 e, 11,15,17,21,24,26,27,30,31,32$, 35,36 , and 38 ; and pathotype $126-5,6,7,11$ is virulent for resistance genes $\operatorname{Sr} 5,7 b, 8 a, 8 b, 15$, and 17 and avirulent for resistance genes $\operatorname{Sr} 6,9 b, 9 e, 9 g, 11,21,24,26,27,30,31,32,35$, 36 , and 38 . The four isolates of $P$. graminis f. sp. tritici were selected to represent a range of pathogenicities with respect to known genes for resistance in Triticum aestivum. The three additional isolates also were used because many barley genotypes are susceptible to $P$. graminis f. sp. secalis and hybrids between forma speciales secalis and tritici.

\section{Generation of gene constructs.}

Standard cloning and DNA manipulation was carried out as described by Sambrook and associates (1989). Rpl-D ubiquitin and actin promoter constructs were generated containing the promoter, $5^{\prime}$ untranslated leader, and first intron of a maize polyubiquitin gene (Christensen et al. 1990) and rice actin 1 gene (McElroy et al. 1991), respectively.

\section{Cereal transformation.}

Maize callus was established from immature embryos of glasshouse-grown Hill maize, which is highly susceptible to all $P$. sorghi isolates used in this study. Transformation was performed with a particle inflow gun using tungsten as the micro-carrier. Plasmids containing genes of interest were cobombarded in equimolar concentrations with pAHC25, which encodes a uidA reporter gene (Jefferson et al. 1987) and BARselectable marker gene (Thompson et al. 1987), each under the control of a maize polyubiquitin promoter (Christensen et al. 1990). Callus was cultured under a selection regime of glufosinate at $10 \mathrm{mg} /$ liter for 4 to 5 months. Following selection, tis- sue was assayed for GUS expression and adult plants regenerated as described by Songstadt and associates (1996).

Immature wheat embryos, following 3 to 5 days of preculture, were transformed biolistically with plasmids containing genes of interest and either pAHC25 (described above) or pCMneoSTLS2, which encodes an intron-containing neomycin phosphostransferase gene regulated by a CaMV 35S promoter (Maas et al. 1997). Wheat callus was cultured under selection before shoot and root formation was initiated (modified from Altpeter and associates [1996]). T0 plants were transferred to soil, screened for transgene integration, and selffertilized to generate $\mathrm{T} 1$ progeny.

Transgenic barley was generated by Agrobacterium sp.mediated transformation using hygromycin as a selective agent, as described by Tingay and associates (1997).

\section{DNA and RNA blot analyses.}

DNA and RNA extraction and gel blot analyses were carried out essentially as described by Collins and associates (1999). To counter potential somatic sectoring in lines containing DS1 transpositions, the same tissue homogenates were used for RNA and DNA analyses. Probes PR1 and PR2 were used for nucleic acid hybridization. Probe PR1 was PCR amplified using M13 (-20) and M13 reverse primers (Stratagene, La Jolla, CA, U.S.A.) from a cloned 480-bp fragment, previously called PIC20 (accession number AF056160) by Collins and associates (1998), that shows $96 \%$ homology to the NBS region of the Rpl-D gene (accession number AF107293) from nucleotides 1,448 to 1,903 . Probe PR2 is a 561-bp fragment (nucleotides 4,020 to 4,580 of the $R p 1-D$ gene sequence) that encodes the $3^{\prime}$ end of the LRR region of the Rpl-D gene and the first $150 \mathrm{bp}$ of the $3^{\prime}$ untranslated sequence, including intron 2. This probe was PCR amplified using primers P6 and P2 (Fig. 1).

\section{Maize cDNA clone isolation and analysis.}

Previously, Collins and associates (1999) screened a $h R p l-D$ maize cDNA library constructed from rust-infected leaf RNA to identify full-length $R p 1-D$ cDNA clones. As part of this screen, $1.4 \times 10^{6} \mathrm{pfu}$ were hybridized with probe PR1 leading to the isolation of 84 positive clones. Of these clones, 65 were derived from the Rpl-Cin4 gene based upon homology to the retrotransposable element sequence of this gene, whereas 12 clones showed homology to a $3^{\prime}$ region of Rpl-D (nucleotides 1,924 to 2,712 of the published $R p l-D$ sequence, accession number AF107293) that is not present in the truncated Rpl-Cin4 gene. These later clones were retained as potential full-length cDNA clones of the Rpl-D gene. Sequence analysis of the 12 clones retained identified 7 clones that did not contain a full-length $3^{\prime}$ end. Four of these clones had polyA tails varying between 0 and $18 \mathrm{bp}$ in length. Because the polydT primer used for reverse transcription during cDNA library construction contained 18 thymidine bases, it could not be ruled out that these latter four clones have arisen from incorrect annealing of the polydT primer used during the reverse transcription reaction; therefore, these clones were no longer considered. The remaining three clones (Fig. 6D, clones 1 to 3 ) were shown to unambiguously encode prematurely truncated and polyadenylated $R p 1-D$ transcripts. The polyA tail present in these three clones varied between 20 and 23 bases in length. Based upon the points of truncation of these clones, the additional As contained in these sequences are not derived from the $R p l-D$ gene and, therefore, are part of a polyA tail.

\section{RT-PCR analyses.}

For RT-PCR analysis, total RNA was reverse transcribed with a Promega cDNA synthesis kit (Promega Corp., Madison, 
Table 2. Primers used for reverse-transcription polymerase chain reaction analyses

\begin{tabular}{|c|c|}
\hline Primer & $5^{\prime}$-primer sequence-3' \\
\hline $\mathrm{P} 1$ & ACGTCAAGGTGC(intron 2)CTTCTC \\
\hline $\mathrm{P} 2$ & GTGTCCAGGAATCGCTCACGG \\
\hline P3 & AAGCTCAGCTAAGTACTCGG \\
\hline $\mathrm{P} 4$ & ATTGGAAGTGTTCTGGTTCCG \\
\hline P5 & GCACACTTGTAATCAATCCAATTG \\
\hline P6 & CCTGAACTCTGGAGCTTCAA \\
\hline $\mathrm{P} 7$ & CTCATAATGAGACAGAGTGGG \\
\hline P8 & GCCCTCAAGGACATTGTACTC \\
\hline P9 & GCCCGACGGAGCTGCTTC \\
\hline P10 & TTCTCTGGAGCAGAAATCAAAGACCAAG \\
\hline $\mathrm{F} 1$ & AACGAAGCAGTTAATCTATTCTTCTC \\
\hline NBSR1 & GTCACTCСТTCСТTTCACAАT \\
\hline PoldT $_{(23)}$ & TTTTTTTTTTTTTTTTTTTTTTT \\
\hline $\operatorname{polydT}_{(25)} \mathrm{n}$ & тTTTTTTTTTTTTTTTTTTTTTTTT(A/C/G) \\
\hline
\end{tabular}

WI, U.S.A.) and approximately $100 \mathrm{ng}$ of this cDNA was used in PCR reactions. Template cDNA was mixed with $0.2 \mu \mathrm{M}$ each primer, $0.05 \mathrm{mM}$ dNTPs, $1.5 \mathrm{mM} \mathrm{MgCl}_{2}$, 10× buffer (New England Biolabs, Beverly, MA, U.S.A.), and 1.25 U Taq DNA polymerase in a total volume of $50 \mu$ l. Amplification occurred during 30 cycles of $94^{\circ} \mathrm{C}$ for $30 \mathrm{~s}, 58^{\circ} \mathrm{C}$ for $30 \mathrm{~s}$, and $72^{\circ} \mathrm{C}$ for $1 \mathrm{~min}$ after an initial step of $94^{\circ} \mathrm{C}$ for $2 \mathrm{~min}$.

Relative comparison of Rpl-D transcription levels in transgenic maize plants was performed by a modification of the multiplex relative RT-PCR method of Spencer and Christensen (1999). Rpl-D cDNAs were amplified from total RNA with primer $\mathrm{P} 4$, which is a gene-specific primer designed from a highly-polymorphic region in the LRR, and primer P5 (Fig. 1) to produce a $1.5-\mathrm{kb}$ amplicon. These products were compared with RT-PCR products from the maize $R p 3$ gene family that were amplified using primers F1 and NBSR1 designed to produce an approximately 880-bp fragment from the $5^{\prime}$ region of $R p 3$ gene transcripts. When maize RNA is used as a template, these latter primers typically amplify this fragment and several smaller fragments.

RT-PCR analysis of transgenic barley and Fielder wheat lines was essentially as described in Ayliffe and associates (1999) using primer P6 for reverse transcription and primer $\mathrm{P} 1$ + P2 for PCR amplification (Fig. 1). Primer P1 flanks intron 2 of the Rpl-D gene and, therefore, is incapable of amplifying from genomic DNA sequences. RT-PCR analysis of the relative stochiometry of $5^{\prime}$ and $3^{\prime}$ encoding $R p l-D$ transcripts in act-RplD barley lines used primer P8 and P6 for reverse transcription and primers $\mathrm{P} 8+\mathrm{P} 9$ and $\mathrm{P} 2+\mathrm{P} 6$ for PCR amplification (Fig. 1). These primer pairs amplify the $5^{\prime}$ and $3^{\prime}$ region of the $R p 1 D$ gene, respectively (Fig. 1) and, in both cases, the amplicon includes an intron sequence that allowed the discrimination of RNA-derived and genomic DNA-derived amplification products. Primers P2 and P6 also were used for RT-PCR analysis of transgenic Bobwhite wheat lines.

\section{Cloning and characterization}

of truncated $R p 1-D$ transcripts from wheat and barley.

Truncated $R p l-D$ transcripts were RT-PCR amplified from wheat and barley, cloned into a pGEM T-vector (Promega Corp.), and sequenced. A polydT ${ }_{(23)}$ primer was used for reverse transcription of wheat RNA while a polyd $\mathrm{T}_{(25)} \mathrm{n}$ primer (where $n=\mathrm{A}, \mathrm{C}$, or $\mathrm{G}$ ) was used for reverse transcription of barley RNA. The resultant first-strand cDNAs were PCR amplified using the same polydT primer in conjunction with either primer P3, P7, or P10 (Fig. 1). Three different $5^{\prime}$ primers were used because the exact points of transcript truncation were unknown prior to cloning (Table 2).

\section{Rust bioassays.}

Maize seedlings (four-leaf stage) were challenged with $P$. sorghi isolate HII, which is virulent on lines carrying Rpl-D, and isolates IN1 and IN3, which are avirulent on lines carrying $R p 1-D$. Wheat seedlings (14 days old) were challenged with two $P$. triticina isolates and two $P$. graminis f. sp tritici isolates. Barley seedlings (14 days old) were challenged under similar conditions with seven $P$. graminis isolates and one $P$. hordei isolate. For inoculation, spores either were prepared in a mineral oil emulsion or rubbed onto the leaves with talcum powder (1:10) and incubated in mist chambers with $100 \%$ humidity for $16 \mathrm{~h}$. Phenotypic symptoms were screened 7 to 10 days postinoculation.

Infection types on maize plants were rated on a five-grade scale $(0=$ no uredinia; $1=$ some uredinia, but not more than 1 or a few per leaf; $2=$ several uredinia on most leaves; $3=$ numerous uredinia but less than susceptible control plants; $4=$ no noticeable resistance reactions and numbers of uredinia similar to susceptible controls) similar to Hooker (1985). Chlorotic flecks were apparent at sites of infection where uredinia did not form in 0 to 2 reactions in most inoculations. Infection types in wheat and barley were assessed as detailed by McIntosh and associates (1995).

\section{ACKNOWLEDGMENTS}

This article is contribution no. 04-031-J from the Kansas Agricultural Experimental Station, Kansas State University. We thank L. Buza, J. Essig, L. Hac, C. Jackson, K. Newell, and M. Williams for technical assistance; N. Upadhyaya for providing plasmid psk300; G. Brown-Guedira for providing wheat rust isolates; and GrainGene and the United States Department of Agriculture NRICGP grant number 99-35300-7702 for financial support.

\section{LITERATURE CITED}

Altpeter, F., Vasil, V., Srivastava, V., Stoger, E., and Vasil, I. K. 1996. Accelerated production of transgenic wheat (Triticum aestivum L.) plants. Plant Cell Rep. 16:12-17.

Anderson, P. A., Lawrence, G. J., Morrish B. C., Ayliffe, M. A., Finnegan, E. J., and Ellis, J. G. 1997. Inactivation of the rust-resistance gene $M$ associated with loss of a repeated unit within the leucine-rich repeat coding region. Plant Cell 9:641-651.

Ayliffe, M. A., Collins, N. C., Ellis, J. G., and Pryor, A. J. 2000. The maize $r p 1$ rust resistance gene identifies homologues in barley that have been subjected to diversifying selection. Theor. Appl. Genet. 100:1144-1154.

Ayliffe, M. A., Frost, D. V., Finnegan, E. J., Lawrence, G. J., Anderson, P. A., and Ellis, J. G. 1999. Analysis of alternative transcripts of the flax L6 rust resistance gene. Plant J. 17(3):287-292.

Bendahmane, A., Farnham, G., Moffet, P., and Baulcombe, D. C. 2002. Constitutive gain-of-function mutants in a nucleotide binding siteleucine rich repeat protein encoded at the $R x$ locus of potato. Plant J. 32:195-204.

Chakraborty, S., Sarmah, B., Chakraborty, N., and Datta, A. 2002. Premature termination of RNA polymerase II mediated transcription of a seed protein gene in Schizosaccharomyces pombe. Nucleic Acids Res. 30:2940-2949.

Christensen, A. H., Sharrock, R. A., and Quail, P. H. 1990. Maize polyubiquitin genes: structure, thermal perturbation of expression and transcript splicing, and promoter activity following transfer to protoplast by electroporation. Plant Mol. Biol. 18:675-689.

Collins, N., Drake, J., Ayliffe, M., Sun, Q., Ellis, J., Hulbert, S., and Pryor, T. 1999. Molecular characterization of the $R p 1-D$ rust resistance haplotype and its mutants. Plant Cell 11:1365-1376.

Collins, N. C., Webb, C. A., Seah, S., Ellis, J. G., Hulbert, S. H., and Pryor, A. 1998. The isolation and mapping of disease resistance gene analogs in maize. Mol. Plant Microbe Interact. 11:968-978.

Diehn, S. H., Chui, W.-L., De Rocher, E. J., and Green, P. J. 1998. Premature polyadenylation at multiple sites within a Bacillus thuringiensis toxin gene-coding region. Plant Physiol. 117:1433-1443.

Dinesh-Kumar, S. P., and Baker, B. 2000. Alternatively spliced $N$ resistance gene transcripts: their possible role in tobacco mosaic virus resistance. Proc. Natl. Acad. Sci. U.S.A. 97:1908-1913.

Frost, D. V. 1998. Transformation of the Linum usitatissimum resistance 
gene L6 into Nicotiana tabcum. M.Sc. thesis, Australian National University, Canberra, Australia.

Gassmann, W., Hinsch, M. E., and Staskawicz, B. J. 1999. The Arabidopsis RPS4 bacterial-resistance gene is a member of the TIR-NBS-LRR family of disease resistance genes. Plant J. 20:265-277.

Gilmour, J. 1973: Octal notation for designating physiologic races of plant pathogens. Nature 242:620.

Haffani, Y. Z., Overney, S., Yelle, S., Bellemare, G., and Belzile, F. J. 2000. Premature polyadenylation contributes to the poor expression of the Bacillus thuringiensis cry $3 \mathrm{Cal}$ gene in transgenic potato plants. Mol. Gen. Genet. 264:82-88.

Halterman, D., Zhou, F., Wei, F., Wise, R. P., and Schulze-Lefert, P. 2001 The MLA6 coiled-coil, NBS-LRR protein confers AvrMla6-dependant resistance specificity to Blumeria graminis f. sp. hordei in barley and wheat. Plant J. 25:335-348.

Hammond-Kosack, K. E., Tang, S., Harrison, K., and Jones, J. D. 1998. The tomato $C f-9$ disease resistance gene functions in tobacco and potato to confer responsiveness to the fungal avirulence gene product avr9. Plant Cell 10:1251-1266.

Hennin, C., Hofte, M., and Diederichsen, E. 2001. Functional expression of $C f 9$ and Avr 9 genes in Brassica napus induces enhanced resistance to Leptospheria maculans. Mol. Plant-Microbe Interact. 14:1075-1085.

Hooker, A. L. 1985. Corn and sorghum rusts. In: Cereal Rusts, Vol. 2. Disease Distribution. Epidemiology and Control. A. P. Roelfs and W. R. Bushnell, eds. Academic Press, Orlando, FL, U.S.A.

Jarvis, P., Belzile, F., and Dean, C. 1997. Inefficient an incorrect processing of the $A c$ transposase transcript in iae1 and wild type Arabidopsis thaliana. Plant J. 11:921-931.

Jefferson, R. A., Kavanagh, T. A., and Bevan, M. W. 1987. GUS fusion: Bglucuronidase as a sensitive and versatile gene fusion marker in higher plants. EMBO (Eur. Mol. Biol. Organ.) J. 6:3901-3907.

Lawrence, G. J., Finnegan, E. J., Ayliffe, M. A., and Ellis, J. G. 1995. The L6 gene for flax rust resistance is related to the Arabidopsis bacterial resistance gene RPS2 and the tobacco viral resistance gene $N$. Plant Cell 7:1195-1206.

Leister, D., Kurth, J., Laurie, D. A., Yano, M., Sasaki, T., Devos, K., Graner, A., and Schulze-Lefert, P. 1998. Rapid re-organisation of resistance gene homologues in cereal genomes. Proc. Natl. Acad. Sci. U.S.A. 95:370-375

Maas, C., Simpson, C. G., Eckes, P., Schickler, H., Brown, J. W. S., Reiss, B., Salchert, K., Chet, I., Schell, J., and Reichel, C. 1997. Expression of intron modified NPTII genes in monocotyledonous and dicotyledonous plant cells. Mol. Breed. 3:15-28.

Madsen, L. H., Collins, N. C., Rakwalska, M., Backes, G., Sandal, N., Krusell, L., Jensen, J., Waterman, E. H., Jahoor, A., Ayliffe, M., Pryor A. J., Langridge, P., sculze-Lefert, P., Stougaard, J. 2003. Barley disease resistance gene analogs of the NBS-LRR class-Identification and mapping. Mol. Gen. Genomics 269:150-161.

McElroy, D., Blowers, A. D., Jenes, B., and Wu, R. 1991. Construction of expression vectors based on the rice actin 1 (Act1) $5^{\prime}$ region for use in monocot transformation. Mol. Gen. Genet. 231:15-160.

McIntosh R. A., Wellings C. R., and Park R. F. 1995. Wheat Rusts: An Atlas of Resistance Genes. CSIRO Publishing, Melbourne, Australia

Meyers, B. C., Shen, K. A., Rohani, P., Gaut, B. S., and Michelmore, R. W. 1998. Receptor-like genes in the major resistance locus of lettuce are subject to divergent selection. Plant Cell 11:1833-1846.

Mogen, B. D., MacDonald, M. H., Leggewie, G., and Hunt, A. G. 1992. Several distinct types of sequence elements are required for efficient mRNA $3^{\prime}$ end formation in a pea rbcS gene. Mol. Cell Biol. 12:54065414

Noel, L., Moores, T. L., van der Biezen, E. A., Parniske, M., Daniels, M. J., Parker, J. E., and Jones, J. D. G. 1999. Pronounced intraspecific haplotype divergence at the RPP5 complex disease resistance locus of Arabidopsis. Plant Cell 11:2099-2111.

Oldroyd, G. E. D., and Staskawicz, B. J. 1998. Genetically engineered broad-spectrum disease resistance in tomato. Proc. Natl. Acad. Sci. U.S.A. 95:10300-10305.

Parker, J. E., Coleman, M. J., Szabo, V., Frost, L. N., Schmidt, R., van der Biezen, E. A., Moores, T., Dean, C., Daniels, M. J., and Jones, J. D. G. 1997. The Arabidopsis downy mildew resistance gene RPP5 shares similarity to the Toll and Interleukin-1 receptors with $N$ and L6. Plant Cell 9:879-894.

Quesada V., Macknight R., Dean C., and Simpson G. G. 2003. Autoregulation of $F C A$ pre-mRNA processing controls Arabidopsis flowering time. EMBO (Eur. Mol. Biol. Organ.) J. 22:3142-3152.
Richter, T., Pryor, T., Bennetzen, J., and Hulbert, S. 1995. New resistance specificities associated with recombination in the Rpl complex in maize. Genetics 141:373-381.

Rommens, C. M. T., Salmeron, J. M., Oldroyd, G. E. D., and Staskawicz, B. J. 1995. Intergenic transfer and functional expression of the tomato disease resistance gene Pto. Plant Cell 7:1537-1544.

Rothnie, H. M. 1996. Plant mRNA 3'-end formation. Plant Mol. Biol. 32:43-61.

Sambrook, J., Fritsch, E. F., and Maniatis, T. 1989. Molecular Cloning: A Laboratory Manual, 2nd ed. Cold Spring Harbor Laboratory Press, Cold Spring Harbor, NY.

Songstadt, D. D., Armstrong, C. L., Petersen, W. L., Hairston, B., and Hinchee, M. A. W. 1996. Production of transgenic maize plants and progeny by bombardment of Hi-II immature embryos. In Vitro Cell. Dev.-Pl. 32:179-183.

Spencer, W. E., and Christensen, M. J. 1999. Multiplex relative RT-PCR method for verification of differential gene expression. BioTechniques 27:1044-1052.

Staskawicz, B. J., Ausubel, F. M., Baker, B. J., Ellis, J. G., and Jones, J. D. 1995. Molecular genetics of plant disease resistance. Science 268:661667.

Stokes, T. L., Kunkel, B. N., and Richards, E. J. 2002. Epigenetic variation in Arabidopsis disease resistance. Gene Dev. 16:171-182.

Sun, Q., Collins, N., Ayliffe, M., Smith, S., Drake, J., Pryor, T., and Hulbert, S. 2001. Recombination between paralogues at the $r p 1$ rust resistance locus in maize. Genetics 158:423-438.

Tai, T. H., Dahlbeck, D., Clark, E. T., Gaijwala, P., Pasion, R., Whalen, M. C., Stall, R. E., and Staskawicz, B. J. 1999. Expression of the Bs2 pepper gene confers resistance to bacterial spot disease in tomato. Proc. Natl. Acad. Sci. U.S.A. 96:14153-14158.

Tao, Y., Yuan, F., Todd Leister, R., Ausubel, F. M., and Katagiri, F. 2000. Mutational analysis of the Arabidopsis nucleotide binding site-leucinerich repeat resistance gene RPS2. Plant Cell 12:2541-2554.

Tang, X., Xie, M., Kim, Y. J., Zhou, J., Klessig, D. F., and Martin, G. B. 1999. Overexpression of Pto activates defense responses and confers broad resistance. Plant Cell 11:15-29.

Thilmony, R. L., Chen, Z., Bressan, R. A., and Martin, G. B 1995. Expression of the tomato Pto gene in tobacco enhances resistance to Pseudomonas syringae pv. tabaci expressing avrPto. Plant Cell 7:1529-1536.

Thompson, C. J., Novva, N. R., Tizard, R., Crameri, R., Davies, J. E. Lauwereys, M., and Botterman, J. 1987. Characterisation of the herbicide resistance gene bar from Streptomyces hygroscopicus. EMBO (Eur. Mol. Biol. Organ.) J. 6:2519-2523.

Tingay, S., McElroy, D., Kalla, R., Fieg, S., Wang, M., Thornton, S., and Brettell, R. 1997. Agrobacterium tumefaciens-mediated barley transformation. Plant J. 11:1369-1376.

Upadhyaya, N. M., Zhou, X.-R., Zhu, Q.-H., Ramm, K., Wu, L., Eamens, A., Sivakumar, R., Kato, T., Yun, D.-W., Santhoshkumar, C., Narayanan, K. K., Peacock, J. W., and Dennis, E. S. 2002. An iAc/Ds gene and enhancer trapping system for insertional mutagenesis in rice. Funct. Plant Biol. 289:547-559.

Whitham, S., Dinesh-Kumar, S. P., Choi, D., Hehl, R., Corr, C., and Baker, B. 1994. The product of the tobacco mosaic virus resistance gene $N$ : similarity to Toll and the interleukin-1 receptor. Cell 78:11011115 .

Whitham, S., McCormick, S., and Baker, B. 1996. The $N$ gene of tobacco confers resistance to tobacco mosaic virus in transgenic tomato. Proc. Natl. Acad. Sci. U.S.A. 93:8776-878.

Xiao, F., Tang, X., and Zhou, J. M. 2001. Expression of 35S::Pto globally activates defense-related genes in tomato plants. Plant Physiol. 126:1637-1645.

Xiao, S., Charoenwattana, P., Holcombe, L., and Turner, J. G. 2003a. The Arabidopsis genes $R P W 8.1$ and $R P W 8.2$ confer induced resistance to powdery mildew diseases in tobacco. Mol. Plant-Microbe Interact. 16:289-294.

Xiao, S. Y., Brown, S., Patrick, E., Brealey, C., and Turner, J. G. 2003b. Transcription of the Arabidopsis disease resistance genes RPW8.1 and $R P W 8.2$ occurs via a salicylic acid-dependant amplification circuit and is required for hypersensitive cell death. Plant Cell 15:33-45.

Zhang, X.-C., and Gassmann, W. 2003. RPS4-mediated disease resistance requires the combined presence of RPS4 transcripts with full-length and truncated open reading frames. Plant Cell 15:2333-2342.

Zhao, J., Hyman, L., and Moore, C. 1999. Formation of mRNA 3 ' ends in eukaryotes: mechanism, regulation, and interrelationships with other steps in mRNA synthesis. Microbiol. Mol. Biol. Rev. 63:405-445. 